\title{
Administração intranasal do agente antitumoral álcool perílico: estratégia terapêutica para pacientes com glioblastoma recidivado
}

\section{Comunicação preliminar}

\author{
Clovis Orlando da Fonseca*, Marcela D'Allincourt Salazar**, Regina Caetano ${ }^{* * *}$,

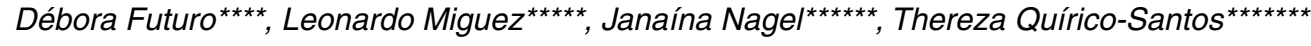 \\ Hospital Universitário Antonio Pedro, Faculdade de Farmácia, Departamento de Biologia Celular \& Molecular e Instituto de Biologia \\ da Universidade Federal Fluminense, Niterói, RJ, Brasil
}

\section{RESUMO}

Álcool perílico $(A P)$ é um monoterpeno com ação antitumoral comprovada, em estudos pré-clínicos, sobre diferentes tipos de tumores induzidos em animais. Fase I e II de ensaios clínicos estão correntemente em desenvolvimento. O mecanismo de ação da atividade antitumoral do AP envolve a inibição da isoprenilação pós-traducional de proteínas $\mathrm{G}$, incluindo a p21-Ras, bloqueando a transdução do sinal. A desregulação da função da p21-Ras, como resultado de mutação, superexpressão ou superativação dos fatores de crescimento, contribui para o crescimento de glioblastoma. A administração intranasal é uma abordagem prática e não-invasiva que permite que agentes terapêuticos que não cruzam a barreira hemato-encefálica alcancem o sistema nervoso central, reduzindo os efeitos colaterais provenientes da administração sistêmica. Este artigo discute a administração intranasal do AP, como potencial estratégia terapêutica multimodal para estas neoplasias e apresenta resultado preliminar em um caso.

\section{PALAVRAS-CHAVE}

Glioblastoma. Álcool perílico. Quimioterapia. Monoterpenos.

\section{ABSTRACT}

Intranasal delivery of anti-tumor agent perillyl alcohol: potential therapeutic alternative for patients with relapsed glioblastoma

Perillyl alcohol $(P O H)$ is a monoterpene with preclinical antitumor activity in several types of tumor in rodent models and is currently under phase I and phase II clinical trials. Its proposed mechanism of action involves inhibition of post-translational isoprenylation of small $G$ proteins, including p21-Ras, thereby blocking signal transduction. Deregulated p21-Ras function, as a result of mutation, overexpresion or growth factor-induced overactivation, contributes to growth of glioblastoma. Intranasal delivery is a practical and non-invasive approach that allows therapeutic agents which do not cross the blood brain barrier to enter the Central Nervous System, reducing unwanted systemic side effects. This article discusses the $\mathrm{POH}$ intranasal delivery as a potential therapeutic option for these neoplasms. The preliminary result in a case is presented.

\section{KEY WORDS}

Glioblastoma. Perillyl alcohol. Chemotherapy. Monoterpenes.

\footnotetext{
* Professor Adjunto de Neurocirurgia do Hospital Universitário Antonio Pedro da Universidade Federal Fluminense.

** Pós-graduando, Universidade Federal Fluminense.

*** Professora Adjunta do Departamento de Biologia Celular \& Molecular do Instituto de Biologia da Universidade Federal Fluminense.

**** Professora Adjunta da Faculdade de Farmácia da Universidade Federal Fluminense.

***** Neurocirurgião do Hospital Estadual Getulio Vargas, RJ.

****** Patologista do Hospital Estadual Getúlio Vargas, RJ.

******* Professora Titular do Departamento de Biologia Celular \& Molecular do Instituto de Biologia da Universidade Federal Fluminense.
} 


\section{Introdução}

Glioblastomas (GBM) são tumores astrocíticos de alto grau de malignidade, de etiologia desconhecida, que acometem principalmente adultos entre 40 e 70 anos de idade e estão localizados, preferencialmente, nos hemisférios cerebrais, na substância branca subcortical $^{23}$. O tratamento cirúrgico torna-se inexeqüível devido à característica extensivamente invasiva desses tumores. As terapias adjuvantes, radioterapia e quimioterapia, assim como novas abordagens, imunoterapia e braquiterapia, não têm conseguido aumentar a média de sobrevida para além de um ano ${ }^{28,37}$. Portanto, torna-se necessária a identificação de novas estratégias terapêuticas que neutralizem as alterações moleculares que contribuem para a transformação glial.

Estudos citogenéticos têm demonstrado freqüentes amplificações e deleções cromossômicas, proporcionando entendimento dos genes envolvidos na tumorigênese dos gliomas de alto grau. GBM comumente superexpressam os oncogenes EGFR e PDGFR e contêm mutações e deleções dos genes supressores tumorais PTEN e TP53. Os GBM primários ou "de novo", comumente superexpressam o EGFR e seu ligante EGFRvIII4 resultando na via de sinalização Ras/MAPK e PI3K/Akt. Os GBM secundários, que progridem a partir de gliomas de baixo grau, comumente contêm mutação do gene TP53 e superexpressam PDGFR, o que resulta na ativação das mesmas vias de sinalização ${ }^{21}$. Todas essas alterações genéticas podem ter impacto na ativação das vias de transdução do sinal que influenciam o comportamento biológico dos GBM, porém, paradoxalmente, servem como alvos para novos planejamentos terapêuticos.

As drogas antineoplásicas disponíveis têm como principal mecanismo de ação o de atingir macromoléculas vitais, como o DNA ou as vias do metabolismo celular, que são críticas para a função das células normais e das transformadas. Como resultado, o tratamento causa muitos efeitos tóxicos e indesejáveis. Em contraste, os compostos naturais atuam inibindo a proliferação das células transformadas, normalizando a atividade dos sinais envolvidos no crescimento celular, tais como instabilidade genética, expressão anormal de genes, transdução anormal de sinal, comunicação intercelular anormal e angiogênese, sem destruir as propriedades estruturais das células normais ${ }^{4}$. O álcool perílico (AP) é um composto natural com propriedade antimitótica de grande interesse na atualidade, cujo mecanismo de ação é a inibição da transdução do sinal com a conseqüente inibição da expressão gênica ${ }^{34}$.

O AP, também chamado p-meta-1,7-dieno-6-ol ou 4-isopropenilciclo-hexenecarbinol, é um monoterpeno encontrado nos óleos essenciais de lavanda, hortelã, sálvia, cereja, limão, bergamota selvagem, gengibre e semente de aipo. Estudos em animais mostraram que o AP é um poderoso agente quimioterápico na regressão de tumores mamários, pancreáticos, hepáticos e prostáticos, além de ser agente quimiopreventivo nos tumores de cólon, melanomas e neuroblastomas ${ }^{3}$. Experimentos in vitro, em cultura de células de origem epitelial neoplásica, mostraram que o AP aumenta a expressão do gene pró-apoptótico Bak. O AP está sendo usado em ensaios clínicos fase I e II em diversos tipos de tumores ${ }^{1,2}$.

\section{Via nasal para aplicação de princípios ativos}

Medicamentos aplicados por via nasal exercem sua ação no trato respiratório superior, podendo atuar na região das fossas nasais, faringe ou laringe. A relevante intensidade da resposta terapêutica sistêmica obtida por essa via deve-se à elevada vascularização da mucosa nasal, à sua extensa superfície, em torno de $150 \mathrm{~cm}^{2}$, e por não ocorrer o efeito de primeira passagem hepática ${ }^{31}$. As preparações nasais de uso tópico, geralmente, visam à obtenção de efeito vasoconstritor, antiinflamatório ou antiinfeccioso. $\mathrm{O}$ interesse da utilização desta via para efeito sistêmico aplica-se, sobretudo, a moléculas sensíveis às enzimas do trato gastrintestinal, como as proteínas e os peptídeos, difíceis de serem administrados por via oral. O uso de uma via alternativa, como a parenteral (subcutânea, intramuscular e intravenosa), tem demonstrado ser desconfortável ao paciente, por exigir freqüentes administrações do medicamento, comprometendo a sua adesão ao tratamento. A fim de contornar esse inconveniente, a via nasal tem sido investigada como alternativa para aplicação de princípios ativos como insulina, progesterona, metoclopramida, propanolol, di-hidroergotamina, desmopressina, atropina, vitamina B12, entre outros. Estudos clínicos mostram o aumento de seis vezes na concentração sangüínea, o dobro da velocidade de absorção e o aumento de 2,5 vezes nas quantidades mensuráveis de vitamina B12 até 48 horas após sua administração via nasal ${ }^{30}$.

Entre as vantagens da liberação nasal pode-se citar a necessidade de doses menores, o efeito terapêutico local se desenvolve instantaneamente, os níveis sistêmicos e a atividade farmacológica são alcançados rápida e relativamente poucos efeitos colaterais. Numerosos princípios ativos podem ser preparados na forma de soluções ou suspensões nasais, na forma de gotas e nebulizadores. Alguns princípios ativos são suficientemente voláteis e podem ser conduzidos ao nariz por meio de um inalador (nebulizador). Estudos têm demonstrado que princípios ativos lipofílicos de baixa massa molecular são bem absorvidos na mucosa nasal através da via transcelular 
(transporte através da membrana). No caso de princípios ativos hidrofílicos, como peptídeos e proteínas, o fator importante para sua absorção parece ser a massa molar. A biodisponibilidade desses princípios ativos é inversamente proporcional à massa molar: moléculas menores são rapidamente absorvidas, enquanto moléculas de massa molar maior têm biodisponibilidade menor. Isso sugere um mecanismo de absorção por difusão, através dos poros aquosos da mucosa nasal ${ }^{13}$.

\section{Resultado preliminar}

Homem de 49 anos de idade, admitido no Serviço de Neurocirurgia do Hospital Estadual Getúlio Vargas, Rio de Janeiro, em 29 de julho de 2004, com relato de cefaléia, distúrbio de memória, episódio de perda de consciência, sem crise convulsiva. A ressonância magnética, de 7 de agosto de 2004, evidenciou volumosa lesão expansiva extra-axial, com alto sinal em T1 e sinal heterogêneo em T2, captando, de forma moderada e heterogênea, o meio de contraste e localizada na região fronto-têmporo-parietal direita. Havia importante edema perilesional determinando compressão das estruturas encefálicas adjacentes, desviando a linha média contralateralmente; suas dimensões foram estabelecidas em $6 \mathrm{~cm} \times 6,4 \mathrm{~cm}$ x $5 \mathrm{~cm}$ (Figura 1A); a análise espectral mostrou importante aumento do nível de lactato no $\mathrm{TE}=35 \mathrm{~ms}$ no centro da lesão.

O tratamento neurocirúrgico consistiu em ampla craniotomia fronto-têmporo-parietal direita, realizada em 13 de agosto de 2004. Após a cirurgia, o exame neurológico evidenciou hemiparesia esquerda. $\mathrm{O}$ laudo anatomopatológico concluiu o diagnóstico de "glioblastoma, grau IV da OMS" (Figuras 1B e 1C). Recebeu alta em 29 de agosto de 2004. Radioterapia em dose de 5.400 cGy foi instituída no período de 8 de setembro a 29 de outubro de 2004.

No dia 4 de novembro, retornou ao Serviço de Neurocirurgia com quadro de sonolência, sem interagir com o meio, hemiplegia esquerda, dificuldade respiratória, impossibilidade de deglutir e desidratado. A tomografia computadorizada (TC) revelou presença de processo expansivo compatível com recidiva de GBM (Figura 2A). Nessa data, e após a assinatura do Termo de Consentimento Livre e Esclarecido (Registro CONEP 9681, processo $\mathrm{n}^{\circ}$ 25000.009267/2004-25), iniciou-se administração de AP a 0,3\%, de 8 em 8 horas, por nebulização. O paciente melhorou o nível de consciência e recebeu alta após quatro dias, para continuar o tratamento em casa. Os exames de sangue, urina e raios-X de tórax, feitos quinzenalmente, mostraram-se dentro dos parâmetros normais. Foram realizadas TC de

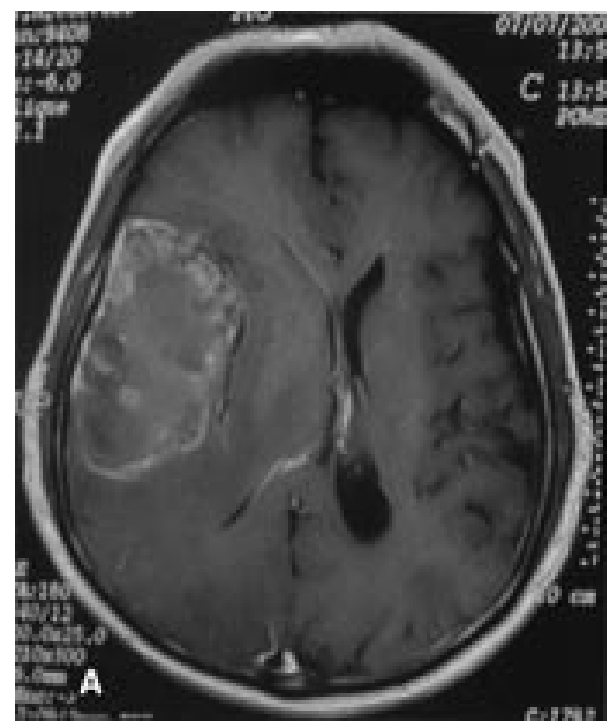

Figura 1A - Ressonância nuclear magnética evidenciando presença de tumor em hemisfério direito.

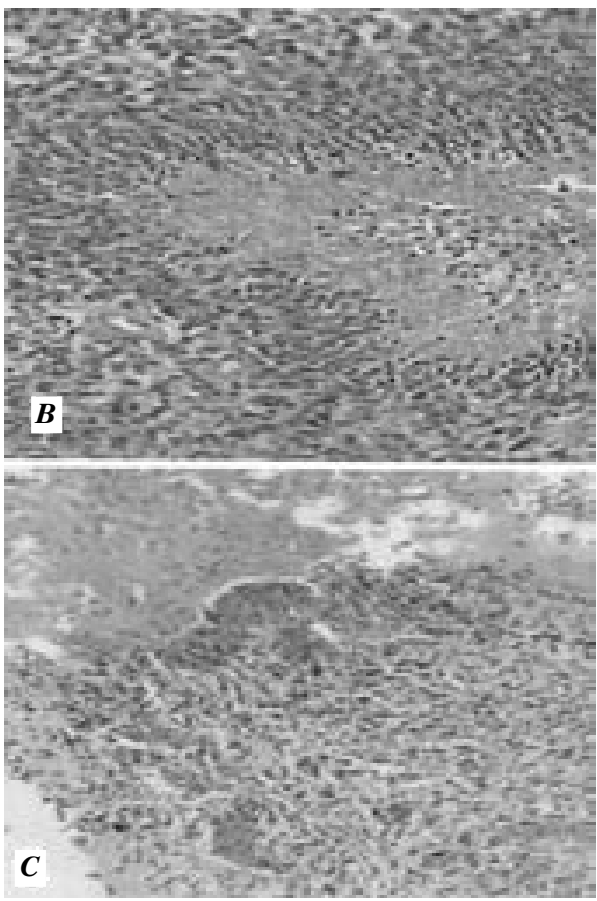

Figura 1 B e 1C-Gioblastoma. Aumento da celularidade e áreas de isquemia e necrose.

tórax, após o primeiro e terceiro mês, com resultados normais. Não há relato de episódios de cefaléia, vômitos, náuseas, diarréia e eructação durante o tratamento. Os exames de imagem (Figuras 2A e 2B) mostram que, aparentemente, houve redução nas dimensões da lesão tumoral e do edema. 

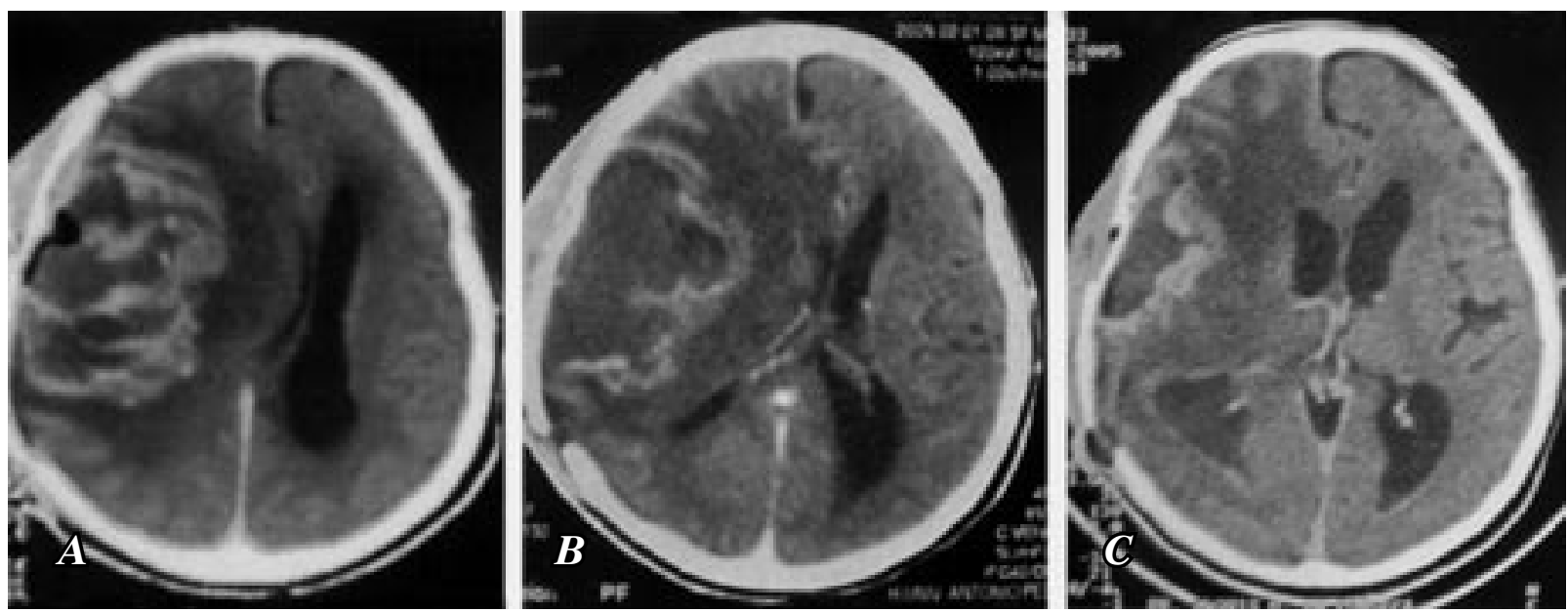

Figura 2 - A: Tomografia computadorizada realizada antes do início do tratamento. B: Após três meses de tratamento. C: Após cinco meses de tratamento com AP administrado por via intranasal.

\section{Discussão}

A morbidade e mortalidade dos GBM são proporcionais à sua capacidade de angiogênese, migração e infiltração dos tecidos adjacentes, o que torna inútil, o esforço de ressecção total desse tumor. As células tumorais infiltrativas, satélites perineuronais, acompanham-se de edema, o que facilita o processo invasivo. Estendem-se através do corpo caloso para os hemisférios cerebrais, criando a imagem de lesão simétrica bilateral, "glioma em asa de borboleta". Essa rápida disseminação pode ser observada na cápsula interna, fórnix, comissura anterior e radiação óptica. Tais estruturas podem tornar-se alargadas e distorcidas, geralmente permitindo a formação de novas massas tumorais em áreas de projeção opostas, e sugerindo imagens neurorradiológicas de glioblastoma multifocal ${ }^{24}$. Pacientes portadores de GBM recidivado têm prognóstico sombrio, com média de sobrevida em torno de quatro meses e os novos quimioterápicos têm demonstrado atividade limitada ${ }^{37}$.

$\mathrm{Na}$ última década, os avanços no conhecimento da biologia molecular dos GBM trouxeram melhor entendimento da gliomagênese, e hoje é aceito que esses tumores resultam de acúmulo de alterações genéticas. Estudos genéticos sugerem que as mutações em genes específicos e aberrações cromossômicas são envolvidas na progressão tumoral dos $\mathrm{GBM}^{27}$. De fato, 45\% dos GBM apresentam alterações em TP53 e no cromossomo 17 , outros $40 \%$ apresentam amplificação do gene EGFR. Estudos mostram que a perda do ponto de checagem do ciclo celular, ou a estimulação mitógena podem levar ao crescimento descontrolado ${ }^{29}$. Estudos demonstram que a Ras-GTP está ativada em amostras de GBM humano, comparando-se com amostras de tecido cerebral normal ${ }^{14}$. A atividade da Ras depende dos mecanismos de isoprenilação e farnesilação, modificações pós-traducionais que são catalisadas pelas enzimas hidroxi-metilglutaril-coenzima-A-redutase e farnesil transferase, respectivamente. Portanto, os agentes inibidores da isoprenilação e da farnesilação da Ras são considerados agentes promissores na estratégia terapêutica para $\mathrm{GBM}^{25}$. O AP é um monoterpeno que inibe a isoprenilação post-traducional e a farnesilação da $\operatorname{Ras}^{7}$ e, portanto, um potencial agente quimioterápico para esses tumores. Ensaios clínicos preliminares fase I em seres humanos foram realizados para determinar a toxicidade do AP. A terapêutica foi instituída por via oral e as dosagens variaram de $4.800 \mathrm{mg} / \mathrm{m}^{2} / \mathrm{dia}$ a 11.200 $\mathrm{mg} / \mathrm{m}^{2} /$ dia, sendo a dose máxima tolerada estabelecida em $8.400 \mathrm{mg} / \mathrm{m}^{2} /$ dia. Os efeitos colaterais significativos - diarréia, náuseas e cansaço-somente foram observados quando doses de $8.500 \mathrm{mg} / \mathrm{m}^{2} /$ dia foram administradas ${ }^{1,2}$. Em nosso estudo, a droga vem sendo administrada por via inalatória, em concentração de $0,3 \%$, de 9 a 12 vezes ao dia, o que perfaz $275 \mathrm{~g}$ a $300 \mathrm{~g}$ ao dia.

A administração de drogas pela via intranasal oferece vantagens sobre a via oral. As drogas podem ser absorvidas rapidamente através da mucosa nasal, resultando em início de ação mais rápido e também evitando a degradação no trato gastrintestinal e no metabolismo hepático. As células receptoras olfatórias estão em contato com o meio ambiente e com o sistema nervoso central (SNC). A hidrofobicidade, a massa molecular e a carga das moléculas irão influenciar a absorção de moléculas da circulação sangüínea para o $\mathrm{SNC}^{12}$. Quanto maior for a solubilidade lipídica de determinada substância ou droga, melhor irá penetrar e 
difundir-se através da barreira hematoencefálica (BHE), atingindo concentrações plasmáticas similares àquelas encontradas após administração endovenosa. Algumas substâncias, como a glicose e os peptídeos, atingem o cérebro através do acoplamento com carreadores especiais capazes de cruzar a $\mathrm{BHE}^{6}$. A difusão através da BHE é o primeiro obstáculo para a administração de drogas no SNC, sendo necessárias intervenções invasivas para administrá-las diretamente no cérebro ${ }^{12}$.

A BHE consiste de monocamada de células endoteliais polarizadas conectadas por complexas zônulas de adesão que fecham os poros do endotélio, normalmente presentes nas membranas endoteliais, separando o sangue do fluido extracelular no parênquima cerebral. A administração intranasal de drogas constitui via nãoinvasiva de tratamento, fornecendo grande superfície mucosa para a absorção de drogas ${ }^{32}$. Essa via de tratamento apresenta diversas vantagens: (a) facilidade e conforto na administração; (b) rápida absorção na circulação sangüínea, devido à intensa vascularização e permeabilidade da mucosa nasal; (c) maior biodisponibilidade e viabilidade, não necessitando sofrer modificações estruturais, uma vez que evita a degradação pelo trato gastrintestinal e pelo metabolismo hepático, alcançando o SNC, via transporte retrógrado, pelos nervos olfatório e trigêmeo ${ }^{35}$ (Figura 3). Ademais, drogas administradas pela via intranasal podem alcançar o SNC através do epêndima, membrana que recobre o plexo coróide, ricamente vascularizado e principal secretor do líquido cérebro-espinal. Muitos compostos que não são capazes de cruzar a BHE penetram através da membrana ependimária ${ }^{8}$.

Dentre as limitações da administração intranasal de drogas, destaca-se o peso molecular; quanto maior for, menor é a biodisponibilidade do agente terapêutico. Após a administração intranasal, a droga é encontrada em diferentes concentrações nas várias regiões do SNC. As alergias ou congestões nasais também podem

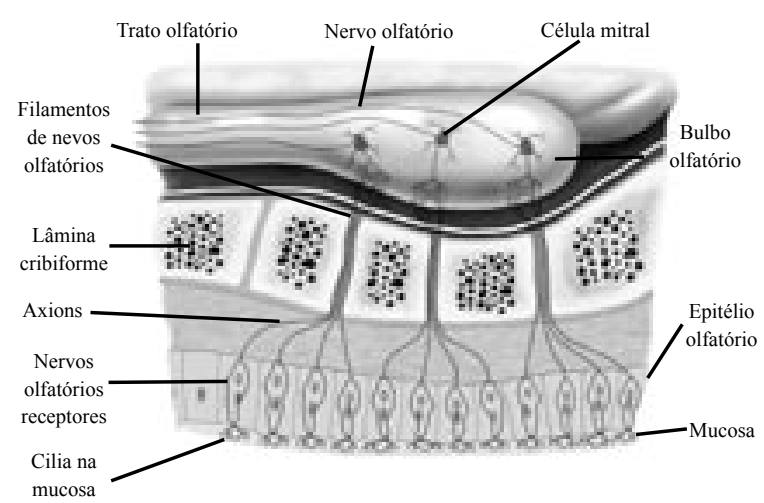

Figura 3 - Esquema da administração intranasal de drogas no SNC.

Fonte: www.leffingwell.com

interferir na atuação da droga devido à irritação da mucosa nasal pelo agente terapêutico, de modo que a droga pode ser susceptível à degradação parcial ou total pela mucosa nasal, devido à presença de aminopeptidases, carboxil-esterases e isoformas do citocromo P450, identificadas como CYP1A, CYP2A E CYP2E na mucosa olfatória ${ }^{35}$.

O SNC é considerado um sítio imunologicamente privilegiado devido à ausência de circulação linfática convencional. Estudos demonstram que uma fração significante ( $14 \%$ a $47 \%$ ) de proteína inoculada no interior do cérebro de animais de laboratório comuns pode ser coletada nos linfonodos cervicais superficiais e profundos. Resultados dessa natureza evidenciam a interação entre o SNC e o sistema imune via linfonodos cervicais e a BHE. Diversos modelos experimentais e/ou de animais portadores de desordens neurológicas mostraram resultados satisfatórios de melhora quando tratados com citocinas e fatores de crescimento por via intranasal ${ }^{8}$. A administração intranasal de nerve growth factor (NGF) reverteu de forma significativa a neurodegeneração causada pela doença de Alzheimer em modelos murinos ${ }^{5}$, assim como a administração de IL-10 e IFN- $\alpha$ suprimiu os sintomas neurológicos decorrentes da esclerose múltipla em ratos ${ }^{33}$. Esses resultados demonstram que a administração intranasal de compostos terapêuticos oferece uma estratégia para atingir o SNC com efeitos colaterais sistêmicos mínimos.

A mucosa nasal é o primeiro sítio de contato com antígenos inalados, sendo drenada pelos linfonodos cervicais superficiais e posteriores. Antígenos solúveis penetram com facilidade no epitélio nasal, entrando em contato com leucócitos intra-epiteliais, da submucosa e células dendríticas ${ }^{26}$. No trato respiratório superior, encontra-se um sistema bastante organizado de tecido linfóide associado à mucosa (NALT) capaz de induzir resposta imunológica sistêmica de maneira mais eficiente que a induzida por imunização oral (Figura 4) ${ }^{9}$. O NALT situa-se no trato respiratório superior, próximo à via de entrada de antígenos externos. Consiste de epitélio folículo-associado (FAE), vênulas endoteliais altas (HEV) e áreas ricas em linfócitos $\mathrm{B}$ e $\mathrm{T}^{20}$. A presença de HEV no NALT mostra a importância destes tecidos como sítios de extravasamento e da recirculação de linfócitos a partir da corrente sangüínea.

O AP, composto presente em óleos essenciais extraídos de diversos vegetais, é rapidamente difundido através da mucosa nasal e da BHE quando administrado pela via intranasal, devido à sua natureza apolar. Esse transporte passivo é responsável pela liberação direta do AP no SNC e no microambiente pulmonar. Ao atingir esses sítios antes de ser metabolizado, a biodisponibilidade e estabilidade do AP é maior do que em relação à administração por via oral, onde os efeitos quimio- 


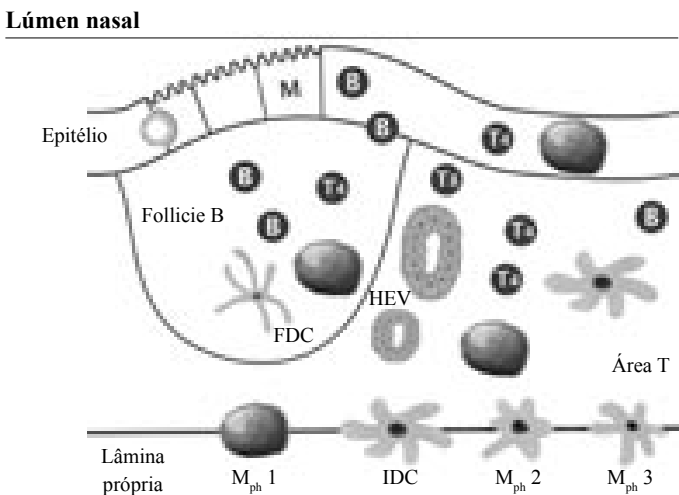

Figura 4 - Compartimentos e composição celular do NALT. B: células B; T4: células T CD4 positivas; T8: células T CD8 positivas;

$M_{p h} 1, M_{p h} 2$ e $M_{p h}$ 3: macrófagos positivos para ED1, ED2 ou ED3, respectivamente;

IDC: célula dendrítica interdigitante;

FDC: célula dendrítica folicular;

HEV: vênula endotelial alta; M: células epiteliais micropregueadas (Kuper e col.1992).

terápicos resultantes são devidos, principalmente, à ação dos seus metabólicos principais: ácido perílico e ácido di-hidroperílico. O AP é administrado por via oral diluído em óleo de soja em ensaios clínicos de fase I e II, quatro vezes ao dia, o que provoca efeitos colaterais como náuseas e vômitos, reduzindo ainda mais a biodisponibilidade e acessibilidade do composto ${ }^{1,2}$. Nossos experimentos ${ }^{11}$ mostraram que o AP $0,3 \% \mathrm{v} / \mathrm{v}$ quando administrado por via intranasal por um minuto, uma e duas vezes ao dia, durante cinco dias não é neurotóxico, não causa nenhuma manifestação sintomatológica e nem altera a citoarquitetura do tecido pulmonar dos animais tratados, assim como nos grupos tratados com etanol ou phosphate buffer saline (PBS). A importância de se usar etanol $70 \%$ como controle deve-se ao fato deste ser o veículo no qual AP pode ser dissolvido. Contudo, observou-se linfocitose no microambiente da mucosa pulmonar, sugerindo ativação do sistema imunológico por camundongos C57 com a inalação do AP, uma e duas vezes ao dia durante cinco dias consecutivos. Vale ressaltar que o efeito foi mais acentuado no grupo tratado com AP duas vezes ao dia.

Nossos estudos ${ }^{10}$ mostraram que o tratamento intranasal com AP $0,3 \%$ v/v não afetou as concentrações séricas de IgA, mas aumentou de forma significativa as concentrações séricas de IgM $(p<0,0413)$, sugerindo o possível papel modulador do AP no sistema de imunidade natural (inato). $\mathrm{O}$ aumento dos níveis de anticorpos naturais circulantes aumenta a capacidade de resposta imune inata do indivíduo, uma vez que a IgM é pentamérica e apresenta dez sítios de ligação com o antígeno, aumentando drasticamente a força de ligação funcional total ${ }^{10}$.
Trabalhos recentes do nosso grupo ${ }^{16-19,36}$, utilizando linhagens de glioblastoma murino (C6) e glioblastoma humano U87MG e A172, mostraram que o tratamento in vitro com doses altas $(30 \% \mathrm{v} / \mathrm{v}$ e $3 \% \mathrm{v} / \mathrm{v})$ e baixas $(0,3 \% \mathrm{v} / \mathrm{v}$ e $0,03 \% \mathrm{v} / \mathrm{v})$ de AP inibiu a proliferação e induziu morte celular das linhagens de glioblastoma U87MG e A172. Resultados semelhantes foram obtidos em experimentos in vivo utilizando ovos embrionados inoculados com células C6 de glioblastoma murinos. Esses experimentos mostraram que o tratamento com AP $0,3 \% \mathrm{v} / \mathrm{v}$ e $0,03 \% \mathrm{v} / \mathrm{v}$ em período inferior a duas horas foi capaz de inibir completamente a migração celular e a angiogênese, evidenciando a atividade antimetastática do AP. Outros experimentos do nosso grupo evidenciaram que o AP na concentração de $1 \mathrm{mM}$ induz apoptose em linhagens celulares de glioblastoma multiforme murino e humanos e células de explante de $\mathrm{GBM}^{15}$.

Estudos fase II com o AP estão em andamento com pacientes portadores de tumores de próstata refratários à terapia hormonal, pulmão, ovário e colorretal. As doses usadas variam de $4.800 \mathrm{mg} / \mathrm{m}^{2} / \mathrm{dia}$ a $11.200 \mathrm{mg} / \mathrm{m}^{2} / \mathrm{dia}$, por via oral ${ }^{2}$. A dose máxima diária tem sido de 8.400 $\mathrm{mg} / \mathrm{m}^{2} /$ dia. Não se encontraram, na literatura, relatos de tratamento com AP por via intranasal para tumores cerebrais primários. Baseado nos resultados obtidos em nossos experimentos e na literatura médica, está sendo desenvolvido o estudo fase II do AP em pacientes com GBM recidivado. O projeto visa tratar 20 pacientes no período de 24 meses, quando se procurará determinar a toxicidade, a dose máxima tolerada e os efeitos antitumorais dessa substância.

\section{Conclusão}

A despeito dos resultados preliminar promissor, obtido em nosso estudo, é prematuro tecer conclusões. Contudo, a administração intranasal do AP, um método rápido, não-invasivo e de baixo custo, apresenta perspectiva na estratégia terapêutica adjuvante para pacientes com glioblastoma recidivado.

\section{Referências}

1. AZZOLI CG, MILLER VA, KARID LM: A phase I trial of perillyl alcohol in patients with advanced solid tumors. Cancer Chemother Pharmacol 51:493-8, 2003.

2. BAILEY HH, LEVY D, HARRIS LS, SCHINK JC, FOSS F, BEATTY P, WADLER S: A phase II trial of daily perillyl alcohol in patients with advanced ovarian cancer: Eastern Cooperative Oncology Group Study E2E96. Gynecol Oncol 85:464-8, 2002. 
3. BELANGER JT: Perillyl alcohol: applications in oncology. Altern Med Rev 3: 448-5, 1998.

4. BOIK J: Natural Compounds in Cancer Therapy. $1^{\text {st }}$ ed. Princeton, Minessota USA, Oregon Medical Press, 2001.

5. CAPSONI S, GIANNOTTA S, CATTANEO A: Nerve growth factor and galantamine ameliorate early signs of neurodegeneration in anti-nerve growth factor mice. Proc Natl Acad Sci U.S.A 17:12432-7, 2002, Epub Aug 30, 2002.

6. COMMITTEE ON DRUGS: Alternative routes of drug administration--advantages and disadvantages (subject review). Pediatrics 100:143-52, 1997.

7. CROWELL PL, RES Z, LIN S, VEDEJS E, GOULD MN: Structure-activity relationships among monoterpene inhibitors of protein isoprenylation and cell proliferation. Biochem Pharmacol 47:1404-15, 1994.

8. CSERR HF, KNOPF PM: Cervical lymphatics, the bloodbrain barrier and the immunoreactivity of the brain: a new view. Immunol Today 13:507-12, 1992.

9. CZERKINSKY C, ANJUERE F, MCGHEE JR et al.: Mucosal immunity and tolerance: relevance to vaccine development. Immunol Rev 170: 197-222, 1999.

10. D'ALLINCOURT MS, FONSECA CO, LAGROTA-CANDIDO J, QUIRICO-SANTOS T: Inalação de camundongos C57BI6 com álcool perílico aumenta o perfil das populações de células citotóxicas. Simpósio de Neuroimunologia Universidade Federal Fluminense, Rio de Janeiro, 2004.

11. D'ALLINCOURT MS: Efeito da administração intranasal do monoterpeno álcool perílico nas subpopulacões dos órgãos linfóides periféricos e do sistema de mucosa de camundongos C57BI6. Monografia de conclusão de graduação de curso de Biologia. Instituto de Biologia Universidade Federal Fluminense, Rio de Janeiro, 2004.

12. DAHLIN M, BERGMAN U, JANSSON B, BJORK E, BRITTEBO E: Transfer of dopamine in the olfactory pathway following nasal administration in mice. Pharm Res 17:737-42, 2000.

13. DONOVAN MD, FLYNN GL, AMIDON GL: The molecular weight of nasal absorption: the effect of absorption enhancers. Pharm Res 8:808-15, 1990.

14. FELDKAMP MM, LALA P, LAU N, RONCARI L, GUHA A: Expression of activated of epidermal growth factor receptors of Ras-guanosine triphosphate and mitogen-activated protein kinase in human glioblastoma multiforme specimens. Neurosurgery 45:1442-53, 1999.

15. FERNANDES J, FONSECA CO, TEIXEIRAA, GATASS CR: Perillyl Alcohol Induces Apoptosis. In: Human Glioblastoma Multiforme Cells. Oncol Rep 13:943-7, 2005.

16. FONSECA CO, FERNANDES J, QUIRICO-SANTOS T, CARVALHO MGC, GATASS CR: Biologia molecular dos glioblastomas: perspectivas terapêuticas do monoterpeno álcool perílico. J Bras Neurocir 14:39-42, 2003.

17. FONSECA CO, LANDEIRO JA, CLARK SS, QUIRICOSANTOS T, CARVALHO MGC, GATTASS CR: Recent advances in the molecular genetics of malignant gliomas disclose targets for antitumor agent perilyl alcohol. Surgical Neurology (in press).

18. FONSECA CO, QUIRICO-SANTOS T, CARVALHO MGC: Efeitos do tratamento in vitro do álcool perílico em linhagens de glioblastomas humanos. Arq Bras Neurocir 22:56-62, 2003.

19. FONSECA CO: Efeitos do tratamento in vitro e in vivo do monoterpeno álcool perílico no crescimento e controle da expressão gênica no glioma de alto grau. Dissertação (Mestrado). Faculdade de Medicina, Universidade Federal do Rio de Janeiro, Rio de Janeiro, 2003.

20. FUKUYAMA S, HIROI T, YOKOTA Y et al.: Initiation of NALT organogenesis is independent of the IL-7R, LtbetaR, and NIK signaling pathways but requires the Id2 gene and CD3(-)CD4(+)CD45(+) cells. Immunity 17:31-40. 2002.
21. GUHA A, FELDKAMP MM, LAU N, BOSS G, PAWSON A: Proliferation of human malignant astrocytomas is dependent on Ras activation. Oncogene 15:755-65. 1997.

22. JANEWAY CA, TRAVERS P, WALPORT M, SHLOMCHIK M: Immunobiology. $3^{\text {rd }}$. Ed. NY, Garland Publishing 2001.

23. KLEIHUES P, BURGER PC, COLLINS VP, NEWCOMB EW, OHGAKI H, CAVENEE WK: Glioblastoma. In: Kleihues P, Cavenee WK (eds): Pathology and genetics: tumors of nervous system. Lyon, IARC Pres, 2000, pp 29-39.

24. KLEIHUESP, OHGAHI: Primary and secondary glioblastomas: from concept to clinical diagnosis. Neuro-oncol 1:44-5, 1999.

25. KOHL NE, CONNER MW, GIBBS J: Development of inhibitors of protein farnesylation as potential chemotherapeutic agents. J Cell Biochem (Suppl 22):145-50, 1995.

26. KUPER CF, KOORNSTRAPJ, HAMELEERS DM, BIEWENGA J, SPIT BJ, DUIJVESTIJN AM, VRIESMAN PJ, SMINIA $\mathrm{T}$ : The role of nasopharyngeal lymphoid tissue. Immunol Today 13:219-24, 1992.

27. LEON SP, AHU J, BLACK PM: Genetic aberrations in human brain tumors. Neurosurgery 34:708-22, 1994.

28. MCDERMOTT MW, BERGER MS, KUNWAR S, PARSAAT, SNEED PK, LARSON DA: Stereotactic radiosurgery and interstitial brachytherapy for glial neoplasms. J Neurooncol 69:83-100, 2004.

29. NEWCOMB EW, MADONIA WJ, PISHARODY S: A correlative study of p53 protein alteration and p53 gene mutation in glioblastoma multiforme. Brain Pathol 3:239-45, 1993.

30. NULDELMAN I: Nasal delivery: A revolution in drug administration. The lastest developments in drug delivery system. Oregon, Aster Publishing Corporation, 1987, pp 43-8.

31. OLIVEIRAMC, CUNHAJRAS, RAMALDES GA, FERREIRA LAM: Vias de administração de formas farmacêuticas. In Gomes MJVM, Reis AMM (eds): Ciências Farmacêuticas: Abordagem em Farmácia Hospitalar. 1 ed. São Paulo, Atheneu, 2003, pp 59-61.

32. PARDRIDGE WM: Transport of insulin-related peptides and glucose across the blood-brain barrier. Ann NY Acad Sci 692:126-37, 1993.

33. ROSS TM, MARTINEZ PM, RENNER JC, THORNE RG, HANSON LR, FREY WH: Intranasal administration of interferon beta bypasses the blood-brain barrier to target the central nervous system and cervical lymph nodes: a non-invasive treatment strategy for multiple sclerosis. J Neuroimmunol 151:66-77, 2004.

34. SHI W, GOULD MN: Induction of cytostasis in mammary carcinoma cells treated with the anticancer agent perillyl alcohol. Carcinogenesis 23:131-42, 2002.

35. TALEGAONKAR S, AND MISHRA PR: Intranasal delivery: An approach to bypass the blood brain barrier. Indian $\mathrm{J}$ Pharmacol 36:140-7, 2004.

36. TERUSZKIN I, ALVES S, SILVA HN, CURIE CM, BOZZA M, FONSECA CO, DA COSTA CMG: Effects of perillyl alcohol in glial cell line in vitro and anti-metastatic activity in chorioallantoic membrane model. Int J Mol Med 10:785, 2002.

37. TRENT S, KONGA, SHORT SC, TRAISHD, ASHLEYS, DOWE A, HINES F, BRADA M: Temozolomide as second-line chemotherapy for relapsed gliomas. J Neurooncol 57: 247-51, 2002.

Original recebido em junho de 2005

Aceito para publicação em agosto 2005

\section{Endereço para correspondência:}

Clovis Orlando da Fonseca

Av. Canal de Marapendi, 1600/1303

22631-050 - Rio de Janeiro, RJ

E-mail: clovisorlando@wnetrj.com.br 


\section{Comentários}

Nos últimos 25 anos, o tratamento dos tumores primários cerebrais apresentou poucos progressos. Apesar dos desenvolvimentos na cirurgia e radioterapia, a sobrevida dos pacientes com glioblastoma multiforme, o mais freqüente dos tumores cerebrais em adultos, permanece desapontadora.

O progresso mais recente, apesar de significativo, ainda está longe do desejado. Diversos estudos mostraram que a adição de quimioterapia à radioterapia pósoperatória aumenta a sobrevida dos pacientes, quando comparada com a radioterapia isolada ${ }^{3}$. Em artigo recente $^{4}$, mostrou-se que a associação de quimioterapia com a droga temozolamida, seguido de temozolamida adjuvante, aumenta, de forma significativa, a sobrevida dos pacientes. A sobrevida média dos pacientes submetidos ao tratamento combinado foi de 14,6 meses e a sobrevida em dois anos foi de $26,5 \%$, comparado a 12,1 meses e $10,4 \%$ dos pacientes submetidos à radioterapia isolada. A partir de então, o tratamento padrão, recomendado internacionalmente, tem sido a radioterapia associada à temozolamida nos pacientes portadores de glioblastoma multiforme.

Diversos fatores têm sido apontados como responsáveis por essa melhora de resultado, sendo talvez o mais importante deles a utilização da quimioterapia concomitante e durante todos os dias de radioterapia. Apesar de a incidência de toxicidade relacionada ao tratamento ter sido bastante baixa, o tratamento tem custo financeiro significativo e, até o momento, não se encontra disponível na rede pública, apesar de a medicação já ter sido liberada pelas agências reguladoras nacionais e ser comercializada no país.

Fonseca e col. apresentam uma interessante linha de pesquisa no tratamento do glioblastoma multiforme. A droga utilizada, o AP é um lípide derivado de plantas, que apresenta atividade antitumoral em estudos pré-clínicos. Seu mecanismo de ação ainda não está completamente esclarecido, porém parece atuar de forma significativa na p21-Ras, bloqueando o sinal de transdução, atuando na diferenciação e apoptose. Alguns estudos encontramse em andamento, com resultados iniciais promissores, especialmente em células tumorais de câncer de pulmão e como rádio-sensibilizador em células de gliomas ${ }^{2,5}$. Outros estudos têm sido conduzidos em câncer de próstata, mama, ovário e colorretal.

Alguns fatores devem ser ressaltados no estudo aqui apresentado. Primeiro, o efeito terapêutico aqui evidenciado pela redução tumoral observada no exame radiológico e ausência de toxicidade ao tratamento. Segundo, a via de administração selecionada, de fácil emprego e baixo custo. A via de administração talvez tenha sido a causa da baixa toxicidade apresentada, pois um dos principais problemas com a administração de AP tem sido os efeitos gastrintestinais (náuseas e vômitos), causados pela administração oral da droga ${ }^{6}$. Terceiro, o custo do tratamento, apesar de não mencionado no estudo, o AP apresenta custo baixo, o que o torna de fácil implantação em saúde pública.

Ainda temos um longo caminho a percorrer no tratamento dos gliomas cerebrais. Porém, qualquer avanço só será alcançado através dos estudos clínicos. Devemos, assim, encorajar nossos pacientes a participar dos estudos em andamento. Como médicos, deveríamos fazer um esforço conjunto, na criação de grupos nacionais de tratamento e pesquisa de patologias como essa, onde o sucesso só será alcançado através do esforço conjunto. Enquanto isso, devemos encorajar e comemorar pequenas vitórias como esta.

Cid Buarque de Gusmão

Diretor do Centro de Oncologia do Hospital 9 de Julho, São Paulo, SP. Membro da Sociedade Brasileira de Oncologia Clínica, American Society of Clinical Oncology, European Society for Medical Oncology. Vice-presidente da Sociedade Brasileira de Oncologia Clínica (1998-2001). Presidente da Sociedade Paulista de Oncologia Clínica (1998-1999).

Rua Peixoto Gomide, 625 - 01308-020 -

São Paulo, SP . E-mail: cid.gusmao@attglobal.ne

\section{Referências}

1. AZZOLI CG, MILLER VA, KARID LM et al.: A phase I trial of perillyl alcohol in patients with advanced solid tumors. Cancer Chemother Pharmacol 51:493-8, 2003.

2. RAJESH D, STENZEL RA, HOWARD SP et al.: Perilly alcohol as a radio/chemosensitizer in malignant glioma. $J$ Biol Chem 278:35968-78, 2003.

3. STEWART LA: Chemotherapy in adult high-grade glioma: a systematic review and meta-analysis of individual patient from 12 randomised trials. Lancet, 359:1011-8, 2002.

4. STUPP R, MASON WP, Van den BRENT MJ et al.: Radiotherapy plus concomitant and adjuvant temozolamide for newly diagnosed glioblastoma. N Engl J Med 352:987-96;2005.

5. XU M, FLOYD HS, GRETH SM et al.: Perillyl alcohol mediated inhibition of lung cancer cell line proliferation: potential mechanisms for its chemotherapeutics effects. Toxicol Appl Pharmacol 195:232-46, 2004. 